\title{
Relationship between Personality and Teacher Effectiveness of High School Teachers
}

\author{
Sandra Buela ${ }^{1}$, Mamman Joseph C. ${ }^{2}$
}

\section{ABSTRACT}

Teacher effectiveness is a matter of the degree to which a teacher achieves the desired effects upon students. Teacher effectiveness is defined as, the extent to which the teacher possesses the requisite knowledge and skills, and teacher performance as the way a teacher behaves in the process of teaching (Dunkin, 1997). It is considered as the teacher's effect on the students as the level of learning been done by teachers and students learn and the period to reach as the level understood by the students from the teacher. Objectives: the present study was conducted to investigate the relationship between personality and teacher effectiveness of High School Teachers in Gulbarga. Method: purposive sampling method was used to select samples from 58 high school teachers of Government Schools in Gulbarga Corporation and survey method was used to collect data by administering NEO-Five Factor Inventory (McCrae and Costa, 1936) and Teacher Effectiveness Scale (Kulsum, 2000) with personal data sheet and the data were analyzed using correlation, t-test and ANOVA methods. Result: the findings revealed that there is a significant relationship between extraversion personality trait and teacher effectiveness $(r=0.28$; $\mathrm{p}<0.05)$, especially with dimension knowledge of subject matter of teacher effectiveness $(\mathrm{r}=0.29$; $\mathrm{p}<0.05)$ and teacher character dimension $(\mathrm{r}=0.34 ; \mathrm{p}<0.01)$ as well as agreeableness personality trait and interpersonal relationship dimension $(r=0.27 ; \mathrm{p}<0.05)$, whereas it was found that there was no significant relationship between teacher effectiveness and personality traits of openness to experience $(\mathrm{r}=0.05)$, neuroticism $(\mathrm{r}=-0.22)$ and conscientiousness $(\mathrm{r}=0.18)$. Experienced teachers are significantly higher in teacher effectiveness than less experienced teachers $(\mathrm{F}=3.66 ; \mathrm{p}<0.05)$.

Keywords: Personality, Teacher Effectiveness.

Personality is considered to be a systematic, organized, developing and being expressed in a person's action. It includes the components as motives, emotions, mental models, and the self. It's also an individual's pattern of character as seem to be thought, emotions, and behavior, together with the psychological mechanisms that are hidden or not hidden behind those patterns. Personality is considered as the common factor of job effectiveness and interest, that is been justified by the definition of Day, Bedeian and Conte (1998) "a common problem with

\footnotetext{
${ }^{1}$ Central University of Karnataka, Karnataka

${ }^{2}$ Assistant Professor, Department of Psychology, School of Social and Behavioural Sciences, Central University of Karnataka, Kadaganchi, Gulburga, Karnataka distribution, and reproduction in any Medium, provided the original work is properly cited.
} 
personality research, in general, and with predicting job-related criteria (effectiveness) in particular, is dealing with the vast array of available personality measures" (Douglas \& Stacey, 2010). " Personality was defined by Gordon Allport (1937) as; "the dynamic organization within the individual of those psychophysical traits that determine his unique adjustments to his environment." He would be referred as a pioneer of modern personality research. Traits are understood as components of emotional, motivational, and social behavior. They are proposed to describe and explain, as well as predict individual differences in human behavior and experience (Herrmann, 1991; McCrae \& Costa, 1995).

\section{Five Personality Factors:}

Extroversion with characteristics of being active, assertive, energetic, enthusiastic, outgoing, talkative, warmth, gregariousness, positive emotions and excitement seeking.

Agreeableness with few qualities of being appreciative, forgiving, generous, kind, sympathetic, trusting, friendly, helpful, considerate, honest and decent.

Conscientiousness with characters of being Efficient, organized, productive, planful, reliable, responsible, thorough, behave ethically, self-disciplined, dutiful.

Openness to experience with characteristics of being Artistic, curious, imaginative, insightful, original, wide interests, introspective, aesthetic.

Neuroticism with few characters of being Anxious, self-pitying, tense, touchy, unstable, worrying, impulsiveness, hostile, depressed.

Teachers are the individuals' who design the communication methods and relevant activities toward the needs, concerns and capabilities of the society they are in. Teachers are not only intended to teach instead they also inspire, entertain, develop creativity, mold the understanding, encourage, inspire hope and imbibes rules to the learners. A teacher's effectiveness is the degree to which the objectives are achieved and the extent to teach in the right way by applying their intellectual readiness, persistence, creativity, and ability to apply knowledge and work productively with others. The qualities of an effective teacher is also been influenced by their communication, expressive skills, personality, ability.

Dunkin (1997) considered that teacher effectiveness is a matter of the degree to which a teacher achieves the desired effects upon students. He define teacher effectiveness as 'the extent to which the teacher possesses the requisite knowledge and skills, and teacher performance as the way a teacher behaves in the process of teaching. 'Teacher effectiveness is meant to be effective as a teacher that means not only being proficient with teaching processes that lead to student achievements but also being a person to facilitate positive change in people's lives. Teacher effectiveness includes characteristics of a teacher, his personality, attitudes etc., and process like teacher-pupil interaction and production variables like outcomes of teacher-learning process, namely pupil achievement. (Umme Kulsum, 2000). 


\section{Significance of the study:}

Teachers are intended to inspire, entertain, develop creativity, mold the understanding, encourage, inspire hope and imbibes rules to the learners along with their teaching. Effectiveness of teachers are based on their performance in the classroom setup but which includes the accountability for student learning and to develop humanitarian characteristics.

Therefore, this study would further look over the relationship between the personality traits and the teachers' effectiveness especially related with extraversion and openness to experience trait. Considerably personality is an essential factor for teacher effectiveness that support the growth of teacher him/her-self, students and the schools they work in. Thus, the understanding of the research problem was thought to be essential to conduct a study on the relationship between "Personality and Teacher Effectiveness of High School Teachers in Gulbarga”.

\section{REVIEW OF LITERATURE}

The present study on the "personality and teacher effectiveness of high school teachers in Gulbarga" is been associated with few works that has been conducted already with regards to its purpose and relevance. It gives an idea of the studies that are conducted in this field. It contains the studies related to different aspects and dimensions of teacher effectiveness with respect to different aspects of personality, teachers’ characteristics and abilities.

Study of relationship between personality and teaching effectiveness revealed that the relationship between personality traits of extraversion, agreeableness and conscientiousness has a positive relation with teaching effectiveness, while the neuroticism and openness have no suggestive relationship with respect to teacher effectiveness (Othman, 2009).

A study on teacher effectiveness revealed that teacher effectiveness includes a teacher's positive professional attitude, positive thinking, and belief in service, self-regulation, dedication, autonomy and guidance to others. The study further reports that an effective teacher intends students to develop positive self-confidence and self-esteem. Additionally an effective teacher will take part enthusiastically in all the activities organized by the school and they preferably have better interaction with colleagues, students and parent (Ahmad, Said, Zeb, Sihatullah \& Rehman, 2013).

Teacher effectiveness includes characteristics of a teacher, his personality, attitudes etc., and process like teacher-pupil interaction and production variables like outcomes of teacher-learning process, namely pupil achievement (Kulsum, 2006).

An effective teacher could create an effective learning environment, care and keep the students enthusiastic in the class hours, promote authentic learning by questions preferring interactive and discussions and manage to organize the classroom with little difficulty and support students to be 
motivated towards success. Whereas the other set of teachers who are contradictory to these characteristics are ineffective teachers. (Walls, Nardi, Minden \& Hoffman, 2002).

The study undertaken to examine teacher effectiveness of school teachers in relation to their job satisfaction, personality and mental health revealed that majority of the teachers were highly effective, nearly half of the teachers in the sample had high job satisfaction, majority of the teachers had high decisiveness, responsibility and heterosexuality personality , whereas majority of the teachers had less emotional stability, masculinity, friendliness, ego strength, curiosity, dominance and self-concept personality, more than half of the teachers in the sample had low mental health.Teacher effectiveness of teachers having high job satisfaction was more than teachers having low job satisfaction among the sample (Goal, 2013).

Teachers at the highest levels of professional expertise and psychological development were capable of balancing the students' intellectual achievements and interpersonal learning in the classroom; used a collaborative approach with students to control the classroom and encouraged creativity and flexibility to create interactive classrooms (Reiman \&Thies- Sprinthall, 1998)

Walsh (2007) viewed that a teacher is having high verbal ability is more effective. Teachers' level of literacy as measured by vocabulary and other standardized tests affect student achievement more than any other measurable teacher attribute.

A study on personality and adjustment correlates of organizational commitment among college teachers found that the teachers temperamentally characterized as conscientious, trusting, adaptable, and practical, regulated by external realities, rule-bound, venturesome, high in selfconcept control, socially bold, emotional and tend to be more committed to their working organizations (Sharma, 2008).

The relation between personality traits of prospective teachers at teacher education centers revealed that the dominant trait among the teachers is openness that had more relevance than other traits (Arif, Rashid, Tahira, \& Akhter, 2012).

The relationship between teacher's personality and teacher student interpersonal behavior is studied by many researchers. In their study Kent, Fisher and Fisher (1995) identified that teachers' personality appears to be consistently associated with their self-image in regard of being friendly, helpful and giving freedom, responsibility and opportunity for independent work in class. This study also provides an idea that there was a greater degree of relation between teacher personality and self-perception.

Murray (1990) identified that effective teachers will be friendly, gregarious, flexible, adaptable and open to change. 
It has been found that effective teachers had significantly better personality adjustment and more favorable attitude towards teaching than ineffective teachers, effective teachers did not show significantly more interest in teaching than ineffective teachers, effective teachers are significantly more emotional stable and finally they are not more extraverted (Chhaya, 1974).

Chayya (2001) while summing up the characteristics of effective teaching, states that effective teachers take personal responsibility for student's learning, provide direction and control of student learning, use a variety of instructional, encourage independent thinking, problem solving and decision making, and provide methods of learning with mental strategies for organising and learning the content being taught.

The characteristics such as warm, kin, friendly, dynamic and motivating students to learn are frequently prescribed to be important characteristics of effective teacher. Among which empathetic and understanding of students' emotions are ranked second to enthusiastic and excitement about teaching (Yilmaz, 2011).

Teacher behaviors that are contributed to teaching effectiveness includes variability, enthusiasm, task-oriented, providing students opportunities to learn, using student ideas, amount of criticism, using structuring comments, types of questions, probing student responses, and level of difficulty of instruction (Rosenshine and Furst, 1971).

Atkins (2005) stated that the extent to which teachers are able to deal effectively with their own and others' emotions can be considered a reflection of their own emotional intelligence. Norton (1980) also stated that most influential dramatic behaviors include controlling mood: telling a good story, catching people to laugh, being entertaining and are concomitant with being perceived as an effective teacher.

The relationship between teachers' characteristics and teacher effectiveness on the scores of commercially available teacher selection instrument were combined into two primary factors summarizing cognitive and non-cognitive teacher skills and it was found that both factors have a modest and statistically significant relationship with student and teacher outcomes, particularly with student test scores. They suggest that, there may be no single factor that can predict success in teaching, using a broad set of measures can help schools improve the quality of their teachers (Rockoff, Jacob, Kane \& Staiger, 2008).

A study conducted on the characteristics of effective and ineffective teaching practices shown that excellent teachers as individuals being (1) respectful, (2) makes classes interesting, (3) fair in evaluating, (4) concerned about students' success, (5) passionate for their subject, (6) friendly, (7) open for questions and discussion, (8) well prepared and organized always, and (9) makes difficult subjects easy to learn. Thereby this study suggests that effective teaching is the 
combination of both personality and ability factors and the main factor remains teacher's personality (Raymond, 2008).

Therefore, it is understood that there is a relation between teacher effectiveness and personality when mainly concerned with the traits of openness, extraversion and emotionally stable. It may also be understood that teacher effectiveness also involves emotional intelligence, strong control over students regards, the techniques used in instructing and fulfilling the expectation of self and students. Teacher effectiveness does involve comfortable communication with other, management skills and availability to the students in and out the class room settings than compared to ineffective teachers. Therefore, teachers to perform effectively are recognized to have the qualities of extraversion and openness to experience.

\section{METHODOLOGY}

\section{Objectives:}

- Find out the relationship between teacher effectiveness and personality of high school teachers.

- Find the relation between teacher effectiveness and selected socio-demographic variables like: gender, experience in years, educational qualification and age.

Hypotheses:

- There will be a positive relationship between teacher effectiveness and Extraversion and Openness to experience traits personality.

- There will be no significant difference in teacher effectiveness with respect to age,

\section{Population:} experience in years, gender and educational qualification of the participants.

The study was conducted on a sample of 58 government school teachers of Gulbarga Corporation both men and women and age range between 31 -60. And their experience ranging from 0-36 years. Purposive sampling method was used in sample selection and data was collected in their respective places of work.

Inclusion Criteria: Teachers, who could read, understand and write in English.

\section{Research Design}

Correlational research design' was been adopted to find out relationship of personality and teacher effectiveness of high school teachers in Gulbarga.

\section{Tools:}

Teacher effectiveness Scale: Teacher effectiveness was assessed using a self-anchoring scale developed by Umme Kulsum in 2000. The scale has five distinguished areas that cover the preparation for teaching and planning, classroom management, knowledge of subject matter, teacher characteristics, and interpersonal relations with a total of 60 items. 
NEO Five Factor Inventory: Test was constructed by Paul T. Costa and Robert McCrae and first published in 1985. This questionnaire is of a self-rating scale and can be administered in a group with five points to rate namely strongly agree, agree, neutral, disagree, and strongly disagree. The NEO-FFI is a 60-item version of Form-s of NEO-PIR that provides a brief comprehensive measure of the five domains of personality -Conscientiousness, Agreeableness, Neuroticism, Extraversion, and openness.

\section{RESULT}

The findings in this study revealed that there is a significant relationship between extraversion personality trait and teacher effectiveness $(r=0.28$; $p<0.05)$, especially with dimension knowledge of subject matter of teacher effectiveness $(\mathrm{r}=0.29 ; \mathrm{p}<0.05)$ and teacher character dimension( $\mathrm{r}=0.34 ; \mathrm{p}<0.01)$. The agreeableness personality trait has a significant relationship with teacher effectiveness especially with interpersonal relationship dimension $(r=0.27 ; \mathrm{p}<0.05)$, whereas it was found that there was no significant relationship between teacher effectiveness and personality traits of openness to experience( $\mathrm{r}=0.05)$, neuroticism( $\mathrm{r}=-0.22)$ and conscientiousness $(\mathrm{r}=0.18)$. Experienced teachers are significantly higher in teacher effectiveness than less experienced teachers $(\mathrm{F}=3.66 ; \mathrm{p}<0.05)$. It has also found that there is no significant difference between teacher effectiveness and age, educational qualification and gender of the participants.

\section{DISCUSSION, LIMITATIONSAND CONCLUSION}

\section{Hypothesis 1:}

There will be a positive relationship between teacher effectiveness and Extraversion and Openness to experience traits personality.

The results of this present study indicates that there is a significant relationship between teacher effectiveness and extraversion personality trait $(\mathrm{r}=0.28 ; \mathrm{p}<0.05)$, especially with the dimensions of knowledge of subject matter $(\mathrm{r}=0.34 ; \mathrm{p}<0.05)$ and teacher characteristics $(\mathrm{r}=0.34 ; \mathrm{p}<0.01)$ of teacher effectiveness scale. This finding is been supported by few other studies conducted previously by Othman (2009), Ahmad(2013), Walls, (2002), Reiman (1998), Walsh (2007), Kulsum (2006), Rosenshine, (1971)and Yilmaz (2011). These studies have found that the teacher effectiveness has close and significant relationship with respect to the qualities of being enthusiastic, dynamic, friendly, social, and so on that supports the hypothesis that has been stated in this study as 'there is positive relationship in teacher effectiveness with respect to extraversion personality trait.

Contrary to the present findings, Chhaya (1974) suggests that effective teachers had significantly better personality adjustment and more favorable attitude and effective teachers are significantly more emotional stable and finally they are not more extraverted moreover according to her findings it is said teacher effectiveness involves the characteristics of an emotional stable person rather than extravert. 
Therefore, it is understood clearly that, the teacher effectiveness includes the qualities of being with full-of energy and often experience positive emotions. They tend to be enthusiastic, actionoriented, face opportunities with excitement. In groups they like to talk, assert themselves, and draw attention to themselves and moreover they tend to be enjoying with their students and colleagues. Thus, it is right that there is a positive relationship between the teacher effectiveness and extraversion personality trait.

In the present study it is found that there is no correlation between the teacher effectiveness and openness to experience personality trait $(\mathrm{r}=0.05)$ and the hypothesis is been rejected. This finding is been supported by the study of Othman (2009), that revealed as there was no suggestive relationship of openness to experience with respect to teacher effectiveness, therefore it in turn support to reject the hypothesis. This may be because they may prefer familiarity over novelty by being conservative and resist change as they may be indulged with their routine activities in their subject matters and may be narrow minded and may also have less creativity.

But this result of the present study is been contradicted by certain other studies as it is expected that teacher effectiveness of teachers had included that qualities of being openness to experience as being intellectually curious, appreciative of art, and sensitive to beauty and they tend to be more aware of their feelings. They tend to think and act in individualistic and nonconforming ways. This hypothesis in this study is been supported by few others as of Kent, et.al. (1995), Murray (1990), Arif, et.al. (2012), Rockoff, et.al. (2008), Goel (2013) and Raymond (2008). These studies suggest that effective teachers are friendly, helpful and open for questions and discussion, well prepared and organized always, and makes difficult subjects easy to learn.

\section{Hypothesis 2:}

There will be no significant difference in teacher effectiveness with respect to age, experience in years, gender and educational qualification of the participants.

It is found that there is no significant difference in teacher effectiveness with respect to age, gender and educational qualification of the participants. But it is seen that there is a significant relationship with teacher effectiveness and experience years $(F=3.66$; $p<0.05)$ of the participants. It may be perceived that the difference between the teacher effectiveness and their experience in years, matter due to the reason as higher the experience would be possible to understand and deal with the teaching profession effectively. Or on the other hand, it may be also seen that the teachers new to the profession perform better than the experienced because they may have a passion for the job they have started with but whereas the experienced teachers may prefer to be stable and resist changes and new ideas as they are more flexible for the things that they are always involved into and do no develop in the field. 


\section{Other findings:}

There is a significant relationship between agreeableness personality traits especially with sub-dimension interpersonal relationship of teacher effectiveness scale.

The agreeableness personality trait reflects individual differences in concern with cooperation and social harmony. These individuals with agreeableness value getting along with others. They are therefore considerate, friendly, generous, helpful, and willing to compromise their interests with others. Teachers with agreeableness might also have an optimistic view of human nature. They believe people are basically honest, decent, and trustworthy. Therefore, effective teachers manage to have well developed interpersonal relationship with their students, colleagues and parents.

This finding is been supported by few other studies conducted previously as Kent, et.al. (1995), Murray (1990), Yilmaz (2011).

There is no significant relationship between teacher effectiveness and conscientious personality trait.

In the present study it is found that there is no significant relation between teacher effectiveness and conscientiousness that may be because of lack of ambition and failure to stay within the lines.

But with contradicting to the result of the present study, other studies of Othman (2009) and Sharma (2008). Therefore, teacher effectiveness may include the qualities of being conscience and may not if not need in certain situations. Thus conscientiousness personality trait qualities may be developed depending upon the situations.

\section{There is no significant relationship between teacher effectiveness and neuroticism personality} trait.

This finding is been supported with the findings of Othman (2009), where it is understood that teachers having the qualities of a neurotic tend to have feeling such as anxiety, anger, or depression, but are likely to experience several of these emotions. Thus these qualities may affect the development of self and moreover it may affect the development of the students and development of the school.

Others studies of Goal (2013), Sharma (2008), Chayya (1974), Yilmaz (2011) and Atkins et al. (2005) suggests that effective teachers are significantly more emotional stable, adaptable, and practical, regulated by external realities, high in self-concept control, socially bold, emotional and tend to be more committed to their working organizations. It is also found that they have decisiveness, responsibility and heterosexuality personality, whereas majority of the teachers had 
less emotional stability, masculinity, friendliness, ego strength, curiosity, dominance and therefore, neuroticism qualities of teachers would lead them to ineffectiveness in their performance.

\section{LIMITATIONS OF THIS STUDY:}

There are few limitations for the present study that may have contributed on the findings and detainment or rejection of the hypothesis. First, the size of the sample is less and the samples were not randomly selected and convincing the samples for participating in the study was difficult.

Secondly, as the study has taken small sample the result may not be generalized or be universally validated and may not be relied widely.

\section{CONCLUSION:}

This study is an attempt to find the relationship between the personality factors and teacher effectiveness of high school teachers in Gulbarga. The study had found that there is a significant relationship between teacher effectiveness and Extraversion personality trait, especially with the sub-dimensions of knowledge of subject matter and teacher characteristics of teacher effectiveness scale and it also found out that there no correlation between Teacher effectiveness and Openness to experience trait of personality. The study conveys that the teachers would preferably be full-of energy and often experience positive emotions. They tend to be enthusiastic, action-oriented and draw attention to themselves and moreover they tend to be enjoying with their students and colleagues, rather they may sometimes prefer to be familiarity over novelty by being conservative and resist change as they may be indulged with their routine activities in their subject matters and may be narrow minded and may also have less creativity.

It is also found that there is no significant difference in teacher effectiveness with respect to gender, age and education qualification of the participants, whereas it may be due to the similarity of job they perform and may have similar kind of attitude and characteristics of being warm, helpful, kin, dynamic, friendly and makes difficult subjects easy to learn. It may also be seen that sometimes they may be intellectually curious, appreciative of art, and sensitive to beauty and they tend to be more aware of their feelings and the tendency of being open to learning.

The study also found that there is significant relation between agreeableness especially with the sub-dimension interpersonal relationship of teacher effectiveness, thus it indicated teacher effectiveness includes qualities being considerate, generous, helpful, and willing to compromise their interests with others. Teachers with agreeableness might also have an optimistic view of human nature may help the teachers to manage well developed relationship with their students, colleagues and parents that help them with wide spread social network and thus also may develop to become an extravert. 
But there is no relation between teacher effectiveness and personality traits as conscientiousness and it is found that neuroticism has no relation with teacher effectiveness, thus it may be understood that effective teachers may be calm, emotionally stable, and free from persistent negative feelings and develop experience a lot of positive feelings where the frequency of positive emotions that may be dependable to the situations.

\section{REFERENCES}

Ahmad, I., Said, H., Zeb, A., Sihatullah, \& Rehman, K. (2013). Effects of Professional Attitude of Teachers on their Teaching Performance: Case of Government Secondary School Teachers in Malakand Region, Khyber Pakhtunkhwa, Pakistan. Journal of Educational and Social Research, Vol. 3 (1), doi: 10.5901/jesr.2013.v3n1p25. Retrieved on: $19 / 2 / 2015$

Allport, G.W. (1966). Traits Revisited, American Psychologist, 21, 1-10

Arif, M. I., Rashid, A., Tahira, S. S., \& Akhter, M. (2012). Personality and Teaching: An Investigation into Prospective Teachers' Personality. International Journal of Humanities and Social Science, 2(17), 161-171. Retrieved from: www.ijhssnet.com. Retrieved on: 9/12/2014

Atkins, P. and Stough, C. (2005) Does Emotional Intelligence Change With Age? Paper presented at the Society for Research in Adult Development Annual Conference, Atlanta.

Chayya, M.P. (2001) Effective teacher- Effective Strategies of Teaching. New Delhi: Alpha publications.

Douglas, G. \& Rutledge. (2007). Models and Predictors of Teacher Effectiveness: A Review of the Literature with Lessons from (and for) Other Occupations. Retrieved from: pnwboces.schoolwires.net/cms/.../models_of_teacher_effectiveness.pdf. Retrieved on: $14 / 9 / 2015$

Douglas, G., McCall, S., McLinden, M. \&Pavey, S. (2009). International review of the literature of evidence of best practice models and outcomes in the education of blind and visually impaired children. National Council for Special Education. Retrieve from: www.rnib.org.uk/sites/default/files/Evidence_base_briefing.doc. Retrieved on: 12/9/2014

Douglas, G. (2010). Reno professional departmental conference. National Social Science Association. United States. Retrieved from: http://www.nssa.us/journals/pdf/NSS_Proceedings_Reno_2010.pdf. Retrievedｏn: $14 / 9 / 2014$

Goal, S. (2013). Teacher effectiveness of school teachers in relation to their job satisfaction, personality and mental health. Retrieved from http://hdl.handle.net/10603/10346

Kent, H. F. D and Fraser, B. (1995). Relationship between Teachers Personality and Teacher Student Interpersonal Behavior. Paper presented at the Australian association for research in education conference. Hobart, Tasmania.

Kulsum, U. (1998) Effect of School Organizational Climate on Job Satisfaction of Teachers, Psycho-lingua, 28, 1; 53-56.

Kulsum, U. (2000) Teacher Effectiveness Scale (KTES), National Psychological Corporation, Agra.

McCrae, R. R. (2001). Reply- 5 Years of Progress: A Reply to Block. Journal of Research in Personality, 35, 108-113. Retrieved from: http://www.idealibrary.com 
McCrae, R. R., \& Costa, P. T. (2010). NEO Inventories, Professional Manual. United States of America. PAR publication.

Murray, E. (1972) Students' Perceptions of Self-Actualizing and Non-Self-Actualizing Teachers. Journal of Teacher Education, 23, 383-387.

Murray, H. G., Rushton, J. P., Paunonen and Sampo V. (1990). Teacher Personality Traits and Student Instructional Ratings in six types of university courses. Journal of Educational Psychology, 82(2), 250-261.

Norton, R. W. and Nussbaum, J. (1980) Dramatic Behaviors of the Effective Teacher in Nimmo, D. (ed.) Communication Yearbook 4, New Brunswick, NJ: Transaction Books, 565-579.

Othman, F. B. (2009). A Study on Personality that influences teaching effectiveness. Retrieved from: http://eprints.usm.my/25478/1/a_study_on_personality_that_influences.pdf. Retrieved on: 17/2/2015

Raymond, S.M. (2008). Effective and Ineffective University Teaching from the Students' and Faculty’s Perspectives: Matched or Mismatched Expectations? (Doctoral dissertation). University of Exeter. Retrieved from: https://ore.exeter.ac.uk/repository/bitstream/handle/10036/40767/RaymondS.pdf?sequenc $\mathrm{e}=1$

Reiman, A. and Thies- Sprinthall, L. (1998) Mentoring and Supervision for Teacher Development. New York; Longman Publishers.

Rockoff, J.E., Jacob, Kane \& Staiger. (2008). Can you recognize an effective teacher when you recruit one? Retrieved from: http://www.nber.org/papers.w14485. Retrieved on: $12 / 9 / 2014$

Rosenshine, B. and Furst, N. (1971) Research on teacher performance criteria. In B. O. Smith (Ed.), Research in Teacher Education - A Symposium (pp. 37-72). Englewood Cliffs, NJ: Prentice Hall, Inc.

Sharma, R. (2008). Personality and Adjustment Correlates of Organizational Commitment among College Teachers. Gyanodaya: The Journal of Progressive Education. 1, Issue: 2 Print ISSN: 0974-1801.

Walls, R.T., Nardi, A.H., Minden, A.M \&Hoofman, N. (2002). The characteristics of effective and ineffective teachers. Teacher Education Quarterly. 29(1). Retrieved from: ltr.sagepub.com/content/10/1/3.refs.Retrieved on: 21/2/2015

Walsh and Tracy (2007) Why Excellent Teaching Matters and what it looks like, Tools for reporting on teaching: What to look in classrooms. (http//www.nbpts.org/).

Yilmaz, A. (2011). Quality problem in teaching profession: qualities teacher candidates feel to be required of teachers. Educational Research and Reviews. 6(14), 812-823. ISSN 1 9903839. Retrieved from: http://www.academicjournals.org/ERR. Retrieved on: 25/2/2015 


\section{APPENDIX}

Table 1.shows the correlation between teacher effectiveness and personality dimensions of extraversion and openness to experience.

\begin{tabular}{ll|l|l|l|l|l}
\multicolumn{2}{c}{ Teacher effectiveness } \\
Personality traits & A & B & C & D & E & Total \\
\hline Neuroticism & -0.18 & -0.13 & -0.23 & -0.23 & -0.24 & -0.22 \\
Extraversion & 0.19 & 0.18 & $0.29^{*}$ & $0.34^{* *}$ & 0.24 & $0.28^{*}$ \\
Openness to change & 0.00 & 0.01 & 0.02 & 0.05 & 0.12 & 0.05 \\
Agreeableness & 0.04 & 0.15 & 0.07 & 0.09 & $0.27^{*}$ & 0.14 \\
Conscientiousness & 0.11 & 0.18 & 0.19 & 0.14 & 0.20 & 0.18 \\
\hline
\end{tabular}

Note: **- significant at 0.01 level.

*-significant at 0.05 level.

A: Preparing and planning; B: Classroom management; C: Knowledge of subject matter;

D: Teacher characteristic; E: Interpersonal relationship.

Table 2.shows the Means and Standard Deviations of various dimensions of teacher effectiveness of the participants

\begin{tabular}{ll|l|l}
\hline Dimensions of Teacher effectiveness & N & Mean & SD \\
\hline Preparing and planning & & 96.84 & 8.65 \\
Classroom management & & 122.55 & 12.11 \\
Knowledge of subject matter & 61.14 & 7.03 \\
Teacher characteristic & & 148.67 & 14.48 \\
Interpersonal relationship & & 96.67 & 8.94 \\
\hline
\end{tabular}

Table 3. shows the means, SDs and t-value of teacher effectiveness of the participants' with respect to their gender.

\begin{tabular}{ll|l|l|l|l|l}
\hline Variable & & N & M & SD & T & Sig. \\
\hline \multirow{2}{*}{ Gender } & Male & 19 & 520.95 & 51.48 & 0.56 & NS \\
& Female & 39 & 528.28 & 44.48 & & \\
\hline
\end{tabular}

Note: NS- 'Not Significant' 
Table 4. shows the ANOVA comparing teacher effectiveness with respect to experience in years, education qualification and age.

\begin{tabular}{|c|c|c|c|c|c|c|}
\hline & & $\begin{array}{l}\text { Sum of } \\
\text { Squares }\end{array}$ & Df & $\begin{array}{l}\text { Mean } \\
\text { Square }\end{array}$ & $\mathbf{F}$ & Sig. \\
\hline \multirow[t]{3}{*}{$\begin{array}{l}\text { Experience In } \\
\text { Years }\end{array}$} & $\begin{array}{l}\text { Between } \\
\text { Groups }\end{array}$ & 14548.38 & 2 & 7274.19 & & \\
\hline & Within Groups & 109069.76 & 55 & 1983.08 & $3.66^{*}$ & 0.05 \\
\hline & Total & 123618.15 & 57 & & & \\
\hline \multirow[t]{3}{*}{$\begin{array}{l}\text { Education } \\
\text { Qualification }\end{array}$} & $\begin{array}{l}\text { Between } \\
\text { Groups }\end{array}$ & 4453.11 & 4 & & 0.49 & NS \\
\hline & Within Groups & 119165.04 & 53 & 2248.39 & & \\
\hline & Total & 123618.15 & 57 & & & \\
\hline \multirow[t]{3}{*}{ Age } & $\begin{array}{l}\text { Between } \\
\text { Groups }\end{array}$ & 7154.00 & 2 & 3577.00 & 1.93 & NS \\
\hline & Within Groups & 92545.53 & 50 & 1850.91 & & \\
\hline & Total & 99699.54 & 52 & & & \\
\hline
\end{tabular}

Note: * - 'Significant at 0.05 level'; NS - 'Not Significant'

\section{Acknowledgement}

I would like to heartily thank Mr. Mamman Joseph. C. for his valuable time, guidance and patience in the whole dissertation period and I also like to thank Dr. Jeyavel Sundaramoorthy and Dr. Vijyendra Pandey for their valuable feedbacks and suggestions on this study.

I warmly thank the administrators and teachers who had given their support, help and had spent their valuable time by participating in this study.

I heartily extend my thanks to my family and my friends in supporting throughout my life and in this study. 